\title{
Foreign civil doctrine of smart contracts
}

\author{
Anna Zakharkina, ${ }^{1, *}$ Olga Kuznetsova $^{2}$ \\ ${ }^{1}$ Perm State University, Department of Civil Law, 614990 Perm, Russia \\ ${ }^{2}$ Perm State University, Department of Business Law, Civil and Arbitration Procedure; Perm Institute of the Federal Penitentiary Service \\ of Russia, 614990 Perm, Russia
}

\begin{abstract}
The article is devoted to a topic of great scientific and practical importance in the modern context of creating a digital economy ecosystemo to the smart contract phenomenon. The article focuses on the foreign civilistic doctrine of the smart contract study. The main discussion questions about the legal and technological nature of the smart contract, the ways of its implementation in the current contract law of each country, the approaches of national legislators to solving this issue and the functional nature of the smart contract are considered. The main disputable problems are the legal and technological nature of the smart contract, the ways of its implementation in the current contract law of each country, the approaches of national legislators to solving this problem and about the functional nature of the smart contract. The article also involves a comparative legal aspect: it analyzes the approaches of the Russian legislator and representatives of the domestic legal doctrine to the smart contract place in the pandect system of Russian civil law in comparison with the foreign legal systems settlement of similar issues. It is noted that using the positive experience of the smart contracts legal regulation should be taken into account when creating and correcting the regulatory platform of the digital economy in the Russian Federation. The article evaluates the legal innovation of Part 2 of Article 309 of the Civil Code of the Russian Federation (RF CC). The description is given of the innovation developers positions given in the Explanatory Note to the relevant draft law; the investigation is performed on the technological terms used in the current version of the RF CC with regard to the electronic form of a deal and smart contract. In addition, the article raises the problem that is well known to the foreign legal doctrine: the problem of the computer code credibility and the distrust of the counterparties of each other. Attention is paid to the advantages of the smart contract, which are discussed by foreign legal scientists, as well as representatives of other related sciences. In the conclusion of the article, the main findings are given that demonstrate the authors' view on the issues considered in the article.
\end{abstract}

\section{Introduction}

Total digitalization, which has affected all spheres of public life, has also befallen the legal system. It is no exaggeration to say that "the smart contract phenomenon is a strong challenge to the current legal system."

Creation of the digital economy ecosystem is the main task facing the Russian and international community. Obviously, the developed foreign countries are "far ahead" in this process; this allowing us to study their positive and negative experience and progress in this area.

\section{Methods}

This study is based on the general scientific dialectical method of cognition, which allowed us to study in dynamics the phenomenon of the smart contract and scientific ideas about it, and to show possible directions and prospects for its future change. The paper uses classical general scientific methods of cognition of any legal research, i.e. analysis, synthesis, deduction, induction, system analysis, historical and functional analysis, comparison and others. The specific scientific research methods were used as follows: formal-dogmatic method - for identifying the legal norms that regulate the smart contract; legal modelling - for developing a model view of the public relations that result from the use of blockchain technology and smart contracts; comparativelegal method - for studying foreign legal regulation of relations that result from the smart contract.

\section{Results}

The analysis of foreign civil science doctrine clearly demonstrates that the study of issues related to smart contracts arouses keen interest among the scientists from different branches of science. One can detect a significant increase in the number of foreign scientific publications specifically devoted to the problems of implementing smart contracts in the last decade. The difficulties of understanding smart contracts are caused by their technological component, namely the blockchain technology that underlies their functioning. Thus, M. S. Cekin, specifying the content of the blockchain technology, is right to note that it is based on a register of data in encrypted form, which is not centralized: the information from the register is 
accessible to all system participants of the system without exception. All operations performed in the blockchain are recorded in the blocks linked to each other. The following should be recognized as the main advantages of the blockchain: absence of intermediaries, equal access of all participants to the system and participation within it, impossibility of tampering $[1, \mathrm{p}$. 315].

Actually, a relationship involving a smart contract, does include an intermediary represented by a programmer. The programmer's task is the transference of the civil obligation terms into the language of programming. That is why we can conclude that a smart contract is "not flexible", since it strictly depends on the information technology conditions. The entire path of a civil obligation implementation depends on how well it is programmed. It is known that the birthplace of the "smart contract" term is Italy. With this, in Italy, a smart contract is understood as a computer program.

In general, it should be noted that in some USA states (for example, California, Nebraska, New York, and others), there are rules that just presume the legality of those relations that arise from a smart contract. A similar rule exists in the Russian civil legislation. In particular, Part 2 of Article 309 of the RF CC establishes a new rule: "The terms of a deal may provide for the discharge by its parties of the obligations resulting from it, when definite circumstances occur, without an additional separately expressed declaration of will by the parties thereof aimed at the discharge of an obligation by way of using the information technologies determined by the terms of the deal".

According to the developers of the relevant draft law V. V. Volodin and P. V. Krasheninnikov, the adopted norm of Part 2 of Article 309 of the RF CC is quite sufficient for the application of smart contracts, no other rules are required. Thus, the rule of Part 2 of Article 309 of the RF CC is aimed at securing a new presumption the presumption of the validity of the performance of an obligation that is committed by a computer program or, in the terminology of Article 309 of the Civil Code of the Russian Federation, "using the information technologies".

According to the developers of the above innovation, smart contracts will ensure the turnover of digital rights. By expressing the will to enter into a contract for the disposal of digital rights, a counterparty who has agreed to perform the obligation using the information technologies is relieved from the necessity to express the will to perform the corresponding obligation, since it is performed automatically. For this particular reason the Explanatory Notes to the relevant draft law use the "selfexecutable deal" term along with the "smart contract" term.

When assessing the draft law, D. V. Fedorov notes that "the wording used by the draft law is not very rigorous" [2, p. 67]. Indeed, the analysis of technological terms leads to the conclusion of legal uncertainty.

For example, the interlinked articles - Article 160 of the RF CC and Article 309 of the RF CC use the terms that are different. In particular, Article 160 of the RF CC which is devoted to the written form of the deal, specifies such terms as "using electronic or other technical means" with regard to the electronic form of the transaction. And Article 309 of the RF CC applies a different term - "using the information technologies" when describing the features of the "automatic" performance of the obligation among other things. In its turn, Article 141.1 of the RF CC covering digital rights contains the "information system" term.

There arises a logical question about the correlation between these technological terms. In fact, the relations that fall under the provisions of Article 160 of the RF CC and Article 309 of the RF CC are mutually conditioned: that is, an obligation that is fulfilled through the use of information technologies, as a rule, arises from a deal that is effected using electronic or other technical means. Therefore, such a terminological difference does not meet the principles of building a pandect system of the Russian civil law and requires unification.

We note that the innovation of Part 2 of Article 309 of the RF CC Civil Code is widely discussed in the scientific literature. When analyzing this innovation, legal scholars qualify the specified norm as an automated performance of obligations, this actually being a smart contract. In particular, in this regard O.S. Grin, E.S. Grin and A.V. Solovyov note that "this decision was the first step towards the legislative regulation of the smart contract concept in Russia" [3, p. 57]. Whereas O. A. Tarasenko believes that Part 2 of Article 309 of the RF $\mathrm{CC}$ is aimed at legalizing the following legislative rule: "a smart contract is recognized as an appropriate way to fulfil obligations" $[4$, p. 8]. E. E. Bogdanova, commenting on paragraph 2 of Article 309 of the RF $\mathrm{CC}$, notes that "the fact of the smart contract execution recorded by a computer program, as a general rule, cannot be challenged" [5, p. 116].

It should be noted that not all civil law scientists and practicing lawyers perceived the innovation of Part 2 of Article 309 of the RF CC favourably. For example, R. Yankovsky and A. Zhuravlev criticize the adopted innovations: the scientists believe that from the point of view of legal engineering, the norm of Part 2 of Article 309 of the RF CC should have been placed in the section dedicated to deals. In addition, the specified innovation should be placed in a new paragraph but not represent a part of Article 309 of the RF CC. R. Yankovsky and A. Zhuravlev do not agree with the terminology chosen by the legislator: in particular, phrase "information technologies" no longer appears anywhere in the RF CC [6, p. 45]. At the same time, Article 141.1 of the RF CC devoted to digital rights contains the "information system" term, which, according to these authors, could be applicable for Part 2 of Article 309 of the RF CC.

So, having the indicated baseline data, we will try to present our own scientific view of the indicated innovations and critical comments thereto.

First, the norm of Part 2 of Article 309 of the RF CC should be recognized as progressive, as the one adopted in the spirit of the "digital economy". The objective and natural consequences of scientific and technological progress, expressed in the widespread spread of digital technologies in all spheres of human life, require 
appropriate legislative innovations: the law must protect those public relations that objectively exist and that affect the rights and legitimate interests of an unlimited number of people.

Second, the norm of Part 2 of Article 309 of the RF $\mathrm{CC}$ contains the following features that allow us to qualify the relevant legal relationship mediated by automated execution:

(a) the conditional nature - i.e. the performance of an obligation against the occurrence of certain circumstances (this normative provision allows us to make a superficial conclusion about some similarity or even identity of the relevant legal relationship with the conditioned performance of an obligation under the model of Article 327.1 of the RF CC);

(b) the digital nature of execution - using information technologies (why did the legislator chose to introduce a new term "information technologies" into the RF CC? In our opinion, between the lines, these particular "information technologies" mean the blockchain system, since it is within its framework that a smart contract exists);

(c) the expression of will which is not typical of the civil law - having no separately expressed additional statement of will aimed at fulfilling the obligation (theoretically speaking, the performance of the obligation does not imply an additional expression of will at all, this allowing one to speak about the automatic performance of the obligation included into a smart contract).

Third, is Part 2 of Article 309 of the RF CC enough for the full implementation of a smart contract into domestic civil legislation? From the point of view of the degree of protection of the respective deal parties, in general, the answer is "yes": with the norm of Part 2 of Article 309 of the RF CC the legislator tells us that both ordinary and digital performance of the obligation (using the "information technologies") are subject to the same legal protection. However, it is obvious that the civil turnover participants will have certain concerns when entering into obligations mediated by a smart contract. Unfortunately, the found examples from judicial practice clearly demonstrate the extreme conservatism of law enforcement agencies, which inevitably face legal relations in which certain digital elements are present. For example, in the known Appeal Ruling of the Ulyanovsk Regional Court of July 31, 2018 for case No. $33-3142 / 2018$, the court concluded that the lack of special legal regulation of cryptocurrency creates insurmountable obstacles to the judicial protection of violated civil rights associated with it. Consequently, the civil turnover participants, when entering into such relations, bear the risk of adverse consequences of such entry.

Thus, Part 2 of Article 309 of the RF CC should be recognized as the first necessary step of the legislator on the way to implementing a smart contract in domestic civil legislation. It is obvious that subsequent changes should be made to Section III - "The General Part of the Law of Obligations", Subsection I - "The General Provisions on Obligations", Chapter 22 - "The Discharge of Obligations", if the internal logic of the RF CC and the pandect system of Russian civil law is to be observed.

\section{Discussion}

In American civil science, a very interesting view is expressed concerning the advantages of a smart contract. It solves the acute problem of trust. In particular, the contractors treat each other with great distrust, this slowing down the civil turnover. In the modern world, a computer code is more trusted, and this makes the blockchain technology and the smart contract resting on it so attractive.

K. J. Fandl identifies three main advantages of the smart contract. The first is the general accessibility of the system, which makes it controllable by any person, this specifically serving for the prevention of corruption and fraud. The second is the availability of a single ledger of all transactions carried out in the system, this allowing one to rely on the legality of the corresponding payments or other operations. The third is the automatic performance that guarantees the security of enforcement. In the latter case, we are talking about a situation in which, for example, late delivery of goods will automatically lead to the compensation of losses to the counterparty who did not receive the goods in due time. In this case, the compensation of losses will take place automatically, without appealing to a judge or arbitrator [7, p. 333].

In the developed foreign legal systems, which have extensive experience in using blockchain technology and smart contracts, there is a significant number of special international platforms through which the application of relevant technologies is carried out. The most popular is Ethereum. N.P. Sheppard, assessing the potential of this platform, notes that Ethereum is positioned as a blockchain application platform on which smart contracts operate in accordance with the program, this eliminating fraud, third-party interference or other illegal action [8, p. 69].

The interest in the smart contracts functioning in foreign legal systems is also great in domestic civil law. For example, N. B. Krysenkova suggests that the legal regulation of smart contracts in foreign jurisdictions could have been based on legal acts covering electronic transactions. Let us note that this approach has both supporters and opponents [9, p. 28]. For example, according to Dutch scientist de Graaf T. J., applying the e-commerce laws to relations that use smart contracts is extremely difficult due to the problem of trust, as well as due to technical aspects. At the same time, it should be notes that most foreign scientists proceed from the need to equate electronic documents with the hard copies [10]. Thus, such norms are provided for by the Information Technology Act adopted in India: the performance of civil obligations using smart contracts in India is based specifically on these norms.

The analysis of foreign civil science doctrine clearly demonstrates that legal fixing of a smart contract is only possible after the fundamental decision is taken by the national legislator regarding the possibility/ impossibility 
of equating smart contracts with traditional civil law contracts. If the legislator proceeds from the fundamental permissibility of such an equation, then there is no need to adopt special laws on smart contracts: it is only necessary to adapt the existing legal norms in view of the technological features of smart contracts. But if the legislator, on the contrary, holds the position of adopting new legal norms specifically dedicated to smart contracts, then a matchable novelization is necessary.

So, the following is one of the fundamental questions: what is the fundamental difference between smart contracts and traditional civil contracts concluded in writing? For example, in the Spanish civil science, one can find the following approach to answering the question: the ways of writing the constructions being compared; the legal consequences; the procedure for implementing the agreed conditions [11]. In the German doctrine, there is a more conservative approach: the contract law is relevant even for those deals that are built on the smart contract model [12, p. 149]. The same approach is also found in other countries: for example, in Malaysia, there is a Law of 1950, which regulates, among other things, smart contracts [13, p. 595]. In the special foreign literature, one can also find the opposite approach: the question of the suitability of the national legal system for the needs of a smart contract is not so relevant $[14$, p. 5]

The multifunctional nature of smart contracts contributes to the fact that equating the smart contracts understood technically and the smart contracts having a legal nature is incorrect: these two understandings should not coincide. In the world of computer engineering, a smart contract does not always "provide service" for civil obligations: the scope of blockchain technology and smart contracts application goes far beyond the law of obligations. Thus, smart contracts are relevant not only for the registration of contractual relations, but also for other spheres of public life: banking, healthcare, payment of music royalties, etc. [15, p. 69].

Identifying the smart contract place in the pandect system of the Russian civil law is obviously predetermined by solving the issue of its generic nature. In the scientific literature, there are doctrinal concepts of the smart contract formulated through such a generic concept as the "agreement". For example, A.I. Savelyev proposes to understand a smart contract as "an agreement that exists in the form of a program code implemented on the blockchain platform" [16, p. 100]. A very similar view on this issue is presented by A.A. Volos, who understands a smart contract as a "programmed contract" [17, p. 5].

However, it is important to emphasize that there are other positions on the subject in the scientific literature. For example, E.A. Gromova, focusing on the difference between such institutions as a contract and a smart contract, comes to the conclusion that a smart contract "can be integrated into contract law as one of the ways to fulfil obligations" [18, p. 37].

L.G. Efimova and O.B. Sizemova have a different position on the matter. These scientists, while differentiating between two generic concepts of a smart contract (the computer code and a civil contract), determine the place of a smart contract in the pandect system of Russian civil law. In particular, in their opinion, a smart contract should be legislatively prescribed in the norms of Chapter 27 of the RF CC that is devoted to the contract concepts and terms [19, p. 29].

V.K. Shaidullina comes to a different conclusion when determining the generic essence of a smart contract, mentioning that "a smart contract is not a type of a contract and is not an independent form, but is primarily a program code" $[20$, p. 22]. The same view is shared by V.M. Kamalyan, who thinks that "a smart contract is nothing but a program code, an algorithm written in a digital language that reflects the terms of a given contract, and cannot be equated with a contract" [21, p. 23].

Thus, all opinions regarding the legal nature of a smart contract and its place in the pandect system of Russian civil law can be grouped into the following concepts. (1) A smart contract is a contract in an electronic form. (2) A smart contract is a way to ensure the performance of an obligation. (3) A smart contract is a program code. Obviously, all conceptual views on the legal nature of a smart contract have an equal right to exist, since they reflect one or another of its features. However, implementing the smart contract institute that has long been known to foreign legal systems, the domestic legislator should take a certain position on this issue.

In contrast to the domestic civil science, which is to some extend in a state of "disorder" regarding the definition of the smart contract essence and nature, as well as all the features resulting from its essence and nature (functions, grounds for occurrence and termination, etc.), foreign civil science adheres to the basic idea that a smart contract is a computer code or a program code. For this particular reason, rather different issues are given priority in the foreign civil law.

Thus, J. Goldenfein and A. Leiter in their joint work speak about the need to "link" transactions that follow the smart contracts use to civil contracts written in a general sense language [22, p. 141]. An interesting observation was made by M. Durovic and A. Janssen: according to these scientists, the "smart contract" term does not accurately reflect the essence of this phenomenon, since a smart contract does not have a specific legal content. So it neither should be called a "contract" nor characterized as "smart", this compromising the use of the "smart" definition in relation to it [23, p. 753].

\section{Conclusion}

A review of the foreign civil law science devoted to smart contracts provided with the following general results, which are of great theoretical and practical importance for the domestic civil legislation reform in the relevant sphere.

The "smart contract" term is used along with the "legal smart contract" term in the foreign countries, this alone allowing solving the Russian civil law problem of 
differentiating between a computer code and a civil contract. Accordingly, the development of the blockchain technology contributes to intensifying the scientific research related to the "legal smart contract".

The "digital economy" topic is a trend in modern domestic and foreign jurisprudence: the issues related to the widespread use of software code and to its harmonization with the law, are of immediate interest. Many scientific works are devoted to them. At the same time, it is worth noting that the range of issues that are the subjects of discussion and are associated with the smart contracts differs from one country to another.

The question of the smart contract nature is practically not raised in the foreign civil law doctrine: foreign researchers unconditionally recognize its technological nature. Therefore, a smart contract, according to the modern foreign doctrine, is a computer code. However, it should be specially emphasized that foreign science proceeds from the differentiation of the "smart contract" and the "legal smart contract" terms.

Despite the long period that the foreign jurisdictions witness the real life existence of public relations associated with the smart contracts use, most foreign researchers of private law are not inclined to legally fix the smart contracts with special legal norms covering them. On the contrary, the idea of the possibility and necessity of adapting classical contract law to the needs of smart contracts is promoted.

In the foreign science, the smart contract term has a multifunctional meaning: its application goes far beyond the civil obligation performance, so the smart contract studies can be found in works on medicine, on organization of educational process in educational establishments, on agriculture and nature use, etc.

In the foreign doctrine, the main focus in studying smart contracts is put on the problem of the translation from the natural language of a civil contract into the language of programming. This, in particular, implies the presence of an intermediary in the relationship where a smart contract is used. It is a programmer whose task is to consider all the features of the future civil contract having the model that he translates from the natural language into the programming one.

\section{Acknowledgements}

The research was prepared within the framework of RF Presidential Grant "Legal Fixing of the Smart Contract as a New Institution of the Russian Federation Law of Obligation that Encourages Counterparties to Cooperate Economically Securely in the Context of Forming the Regulatory Platform of the Digital Economy Ecosystem" (MK-481.2020.6).

\section{References}

1. M.S. Cekin, Blockchain Technology and Smart Contracts in terms of Law of Obligations and Data Protection Law, Istanbul Hukuk Mecmuasi, 77 (2019)
2. D.V. Fedorov, Tokens, Cryptocurrency and Smart Contracts in Domestic Draft Laws from the Perspective of Foreign Experience, Bulletin of Civil Law, 2 (2018)

3. O.S. Grin, E.S. Grin, A.V. Solov'ev, The Legal Construction of a Smart Contract: the Legal Nature and Scope of Application, Lex russica, 8 (2019)

4. O.A. Tarasenko, Digital Transformation of the Banking and Payment Systems of Russia, Business law, 3 (2019)

5. E.E. Bogdanova, Problems of Applying Smart Contracts in Transactions with Virtual Property, Lex russica, 7 (2019)

6. L. Novoselova, A. Gabov, A. Savelyev, A. Genkin, S. Sarbash, A. Asoskov, A. Semenov, R. Yankovsky, A. Zhuravlev, A. Tolkachev, A. Kamelkova, M. Uspensky, R. Krupenin, V. Kislyi, M. Zhuzhzhalov, V. Popov, M. Agranovskaya, Digital Rights as a New Object of Civil Law, Law, 5 (2019)

7. K.J. Fandl, Can Smart Contracts Enhance Firm Efficiency in Emerging Markets? Northwestern Journal of International Law \& Business, 40 (2020)

8. N.P. Sheppard, Can Smart Contracts Learn from Digital Rights Management? IEEE Technology and Society Magazine, 39 (2020)

9. N.V. Krysenkova, Smart-contracts in a Foreign Legal Space, International Public and Private Law, 5 (2019)

10. T.J. de Graaf, From old to new: From internet to smart contracts and from people to smart contracts, Computer Law \& Security Review, 35 (2019)

11. E. Salmeron-Manzano, F. Manzano-Agugliaro, The Role of Smart Contracts in Sustainability: Worldwide Research Trends, Sustainability, 11 (2019)

12. J. Frankenreiter, The Limits of Smart Contracts, Journal of Institutional and Theoretical EconomicsZeitschrift Fur Die Gesamte Staatswissenschaft, 175 (2019)

13. Zain Nor Razinah Binti Mohd, Ali Engku Rabiah Adawiah Engku, Abideen Adewale et al., Smart Contract in Blockchain: An Exploration of Legal Framework in Malaysia, Intellectual Discourse, 27 (2019)

14. R. Brownsword, Regulatory Fitness: Fintech, Funny Money, and Smart Contracts, European Business Organization Law Review, 20 (2019)

15. H. Eenmaa-Dimitrieva, M.J. Schmidt-Kessen, Creating markets in no-trust environments: The law and economics of smart contracts, Computer Law \& Security Review, 35 (2019)

16. A.I. Savelyev, Some Legal Aspects of the Use of Smart Contracts and Blockchain Technologies in Russian law, Law, 5 (2017)

17. A.A. Volos, Smart Contracts and Principles of Civil Law, Russian justice, 12 (2018) 
18. E.A. Gromova, Smart Contracts in Russia: Attempt to Determine the Legal Entity, Law and the Digital Economy, 2 (2018)

19. L.G. Efimova, O.V. Sizemova, The Legal Nature of a Smart Contract, Banking Law, 1 (2019)

20. V.K. Shaidullina, Smart Contracts in the Financial Market: Research Results, Judge, 2 (2019)

21. V.M. Kamalyan, The Concept and Legal Features of Smart Contracts, Lawyer, 4 (2019)
22. J. Goldenfein, A. Leiter, Legal Engineering on the Blockchain: 'Smart Contracts' as Legal Conduct, Law and Critique, 29 (2018)

23. M. Durovic, A. Janssen, The Formation of Blockchain-based Smart Contracts in the Light of Contract Law, European Review of Private Law, 26 (2018) 